\title{
The applying accounting methodology of radar chart for textile production activity in Great Britain
}

\author{
Miguel-Angel Pérez-Benedito \\ Faculty of Economy, \\ University of Valencia, Valencia, ES.
}

\begin{abstract}
The manuscript analyses the management of textile industrial on several countries applying accounting methodology of radar charts. The answer of companies to changes of markets are kinds of management obtained from financial statements when average periods of maturation are axes of a radar chart. Distances between consecutives axes of a radar chart are perimeter distances, which measure tension that transactions entail on respective management areas represented on it. The orientation of perimeter distances measured by internal angles allows obtaining necessary and sufficiency conditions to assess kinds of management respect to accounting financial structures of companies. These relations are visual represented avoiding to apply stochastic methods for analysis. This cause-effect relation supposes there are cultural factors where companies are located, which make conditional on time of conducting business transactions.
\end{abstract}

Keywords: Accounting Methodology; Geographical Maps of Management; Economic culture; Tree-plot Diagram; Graphical Estimation of Companies.

\section{INTRODUCTION}

The perturbation on markets can to have different causes and companies need the adjusting their strategies to continue their activity. The asymmetric information and rationality of decision take side on assessment of management made, and all information about behavior of companies must to be consider justifying that answers to changes of market have been adopted fallowing sentences that those requires [1] [2] [3]. The theory of location companies, theory of transaction cost as well as the Control Environment component of COSO report [4] are not indifferent to the effect of culture on activity of companies, arising new accounting standards [5] 6] and indicators to improve decisions of managers despite markets' instability is present [7], [8].

The accounting methodology of radar chart take on account difficulty of managers to make decisions on unstable economic environments, and manuscript develop the quantitative and qualitative analyzes on the textile manufacturing sector. The methodology can be applied on sort and big companies to explain the multidirectional effect of their decisions on several areas of management represented on a radar chart [9]. The value of economic and financial effects of the making decision process are the annual financial statements of companies, and their average periods of maturation measure time of economic and financial transactions of business activity. These variables are axes or radar chart and applying cosine and sin theorems of plane geometry are obtained positive, independent, objective and normalized indicators. So, a radar chart is a kind of management which represents answers of companies to changes of markets, and the sum of perimetral distances are types of managements. Analyzing the characteristics of several kinds of management, managers know what effects will have their decisions on financial structure of their companies [10] [11]. 
The manuscript has several sections where above issues are considered. The second section presents the accounting methodology of radar chart to apply qualitative and quantitative analysis on textile sector. The qualitive analysis evaluates the behavior of companies by their adopted kind of management obtaining chi2 $\mathrm{p}$-value for years and countries, it allows knowing when companies need overcome the perturbation of market where they develop their activities. Nevertheless, the environment where companies are located has effect on their management, and quantitative analysis measure effects on their financial situation making visual them by three plots. The application of AMRCh on England companies previously to conclusions explains the singular analysis on activity of a company, and conclusions are a summary of those achieved in the different sections of this manuscript.

\section{THE ACCOUNTING METHODOLOGY OF RADAR CHART}

The accounting methodology of radar chart has its reason for being, considering that accounting financial statements of a company are the summary of the decision-making process. Moreover, accounting records are part and counterpart of economic and financial transactions of companies as result of their activities made on a period. The measure of this dynamism are average periods of maturation. Theses dynamic measures are axes of a radar chart and represent answers of companies to changes of markets as well as to environment where companies are located.

The radar chart is a geometrical figure of a making decisions and represents a Kind of management. So, applying the cosine and sine theorems the performance of managers can be measured by mathematical criteria, which are independent of analyst, not affect to value criteria and normalized by the applying those theorems. Kinds of management represented in figure 1 are radar charts of British companies of textile sector.

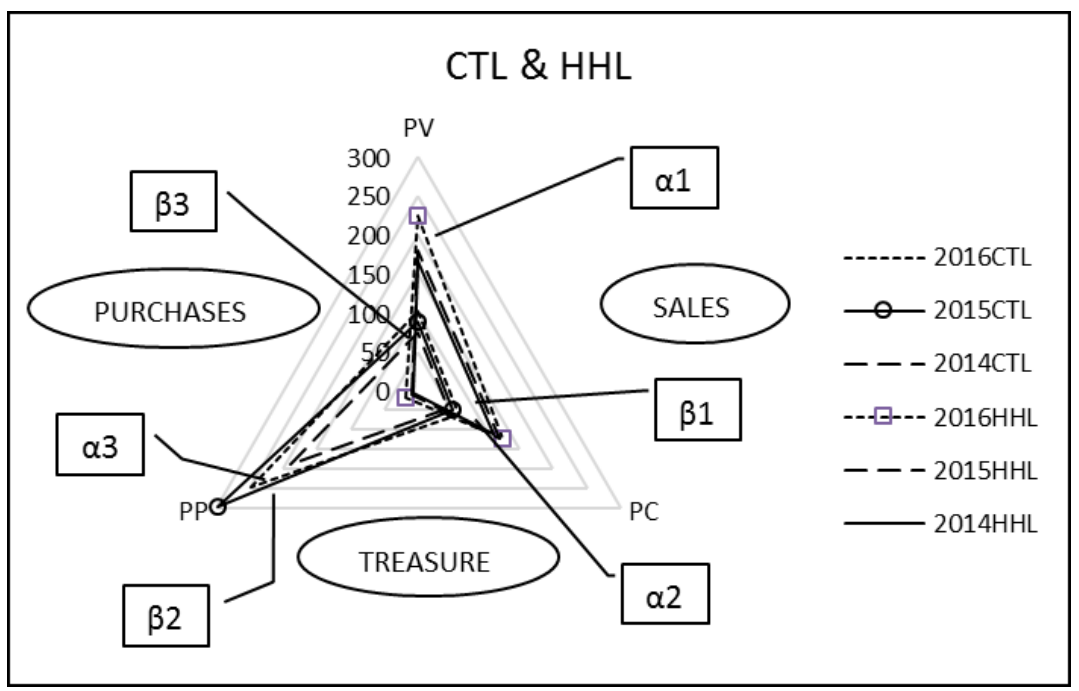

Figure1. Radar charts of British companies

The radars chart in figure 1 are answers of CTL and HHL companies to changes of markets and represent kinds of management. So, average periods of maturation are measures of performance which graphically allows to build the multidirectional effects of managers' decisions on sales, treasure and purchases areas represented on a radar chart. The distances between two axes of a radar chart are tensions of management on represented areas on it, and applying cosine and sine theorems the conditions to achieve optimal of management can be established. 
The cosine and sine theorems are expression 1 and 2, respectively.

$$
\begin{gathered}
P D_{k}^{2}=p_{i}^{2}+p_{j}^{2}-2 \cos 120 * p_{i} * p_{j} \\
\frac{P D k}{\operatorname{sine} 120}=\frac{p i}{\text { sine } \alpha k}=\frac{p j}{\text { sine } \beta k}
\end{gathered}
$$

$\mathrm{K}=1$ (sales area), 2 (treasure area), 3 (purchases area) $\mathrm{i} \neq \mathrm{j} ; \mathrm{i}=\mathrm{j}=1$ (sales), 2 (collect) 3 (payment)

Perimetral distances of expression 1 represent tensions of management on several areas of a radars chart and they allow to contrast activity among year of a same period. The expression 2 allows to get internal angles for building conditions to assess the management made. So that, there are two way for measure the activity of companies, one way to contrast companies' dynamic activity among years of a period and other way to assess their activity yearly.

The permutation without repetition of perimetral distances (PDk) are kinds of management as answers to companies on conditions of management where companies are located. When perimetral distances of a kind of management (KM) are more dilated than others there are less tension on areas of management but their orientation respect to a canonical base could be different and valuing of internal angles take relevance on assess the activity of companies. Values of Internal angles of management areas are necessary conditions to define the kind of management and contrasting PDk by sine theorem the financial and liquidity conditions of sufficiency define optimum of management. The tables 2 and 3 present respectively kind of management as well as their necessary conditions and sufficiency condition of sufficiency and liquidity of transaction.

Table 2. Kind of management and necessary conditions

\begin{tabular}{|c|c|c|c|c|}
\hline KM & Perimeter distancies & Sales area & Treasury area & Purchase area \\
\hline A & PD2 $\geq$ PD3 $\geq$ PD1 & $\alpha 1 \geq \beta 1$ & $\alpha 2>\beta 2$ & $\alpha 3<\beta 3$ \\
\hline B & PD3 $\geq$ PD2 $\geq$ PD1 & $\alpha 1<\beta 1$ & $\alpha 2>\beta 2$ & $\alpha 3 \leq \beta 3$ \\
\hline C & PD3 $\geq$ PD1 1 PD2 & $\alpha 1<\beta 1$ & $\alpha 2>\beta 2$ & $\alpha 3>\beta 3$ \\
\hline D & PD1 $\geq$ PD3 $\geq$ PD2 & $\alpha 1<\beta 1$ & $\alpha 2<\beta 2$ & $\alpha 3 \geq \beta 3$ \\
\hline E & PD1 $\geq$ PD2 $\geq$ PD3 & $\alpha 1 \leq \beta 1$ & $\alpha 2<\beta 2$ & $\alpha 3<\beta 3$ \\
\hline F & PD2 $\geq$ PD1 $1 \geq$ PD3 & $\alpha 1>\beta 1$ & $\alpha 2<\beta 2$ & $\alpha 3<\beta 3$ \\
\hline
\end{tabular}

The table 2 presents perimeter distances which can get same value between tow averages period of maturation and so internal angles define a kind of management according to orientation of PD on each area of management. Kinds of management can be classified into positive and negative. So, kinds of management are positive when $\alpha 2>\beta 2$ and they are negative when $\alpha 2<\beta 2$, according to value of internal angles of treasure area because define different level of tension among Perimeter distances (PD) of purchases and sales areas.

Applying the sine theorem to contrast respective PD of each KM conditions for measuring the financial capacity and liquidity of transactions can be obtained. The table 3 presents sufficiency conditions of financial and liquidity of transactions on several management areas. Sufficiency conditions measure the capacity of an area to obtain financing according to levels of average periods of maturation which delimit an area in radar charts. Conditions of liquidity transactions contrast result of transactions by comparing average periods of an area respects to their effects on other areas. The angles to measure necessary and sufficiency conditions on an area sum 60 degree and liquidity conditions contrast the angular effect with conditions of transactions. When the companies meet both conditions, they reach the optimal management of areas represented in a radial chart. 
Table 2. Sufficiency conditions

\begin{tabular}{|c|c|c|c|}
\hline Management areas & Kinds management & Financial Sufficiency Conditions & Liqudity Transactions Conditions \\
\cline { 2 - 4 } Sales area & A, E, F & $\beta 3 / \alpha 2>1$ & $\alpha 3 / \beta 2>\mathrm{PS} / \mathrm{PC}$ \\
\hline \multirow{2}{*}{ Treasury area } & B, C, D & $\alpha 2 / \beta 3>1$ & $\beta 2 / \alpha 3>\mathrm{PC} / \mathrm{PS}$ \\
\cline { 2 - 4 } & A, B, C. & $\beta 1 / \alpha 3>1$ & $\alpha 1 / \beta 3>\mathrm{PC} / \mathrm{PP}$ \\
\hline \multirow{2}{*}{ Purchases area } & D, E, F. & $\alpha 3 / \beta 1>1$ & $\beta 3 / \alpha 1>\mathrm{PP} / \mathrm{PC}$ \\
\cline { 2 - 4 } & A, B, F. & $\alpha 1 / \beta 2>1$ & $\beta 1 / \alpha 2>\mathrm{PS} / \mathrm{PP}$ \\
\cline { 2 - 4 } & C, D, E. & $\beta 2 / \alpha 1>1$ & $\alpha 2 / \beta 1>\mathrm{PP} / \mathrm{PS}$ \\
\hline
\end{tabular}

The aims of this methodology (AMRCh) is measuring the activity of companies visually according to multidirectional effects of theirs making-decision processes and represented on a radar chart. A radiologist makes a diagnosis by the image obtained from a magnetic resonance and this one must be the position of an accounting analyst observing a radar chat, which is built under the indicated conditions, because he is seen a Kind of management. The cautions that an analyst must consider about the quality of the indicators decay when they are being obtained by application of geometry principles and they also will always have a positive value.

\section{Behavior of textile sector.}

\section{APPLICATION OF AMRCH}

The manuscript assesses companies classified on activities $1310<<$ Preparation and spinning of textile fibers $>>$ and $1320<<$ Weaving of textiles $>>$ of European Classification of Economic Activities (NACE), applying Accounting Methodology of Radar Chart (AMRCh). Checking the database Orbis over license of University of Valencia, the sample of companies of this sector was 537 and adjust them to get their average periods of maturation the analyzed companies are table 1.

Table 1. Companies assesses in manuscript

\begin{tabular}{|c|c|c|c|c|c|c|c|}
\hline Year/kind management & A & B & C & D & E & F & Sum \\
\hline 2008 & 10 & 8 & 38 & 79 & 14 & 13 & 162 \\
\hline 2009 & 18 & 16 & 55 & 60 & 10 & 8 & 167 \\
\hline 2010 & 17 & 16 & 44 & 68 & 11 & 11 & 167 \\
\hline 2011 & 16 & 15 & 42 & 70 & 19 & 9 & 171 \\
\hline 2012 & 19 & 16 & 48 & 67 & 13 & 9 & 172 \\
\hline 2013 & 16 & 14 & 56 & 63 & 14 & 10 & 173 \\
\hline 2014 & 15 & 12 & 59 & 63 & 15 & 9 & 173 \\
\hline 2015 & 10 & 18 & 58 & 67 & 13 & 8 & 174 \\
\hline 2016 & 12 & 22 & 56 & 59 & 14 & 9 & 172 \\
\hline 2017 & 13 & 19 & 53 & 60 & 14 & 9 & 168 \\
\hline sum & 146 & 156 & 509 & 656 & 137 & 95 & 1699 \\
\hline
\end{tabular}

The table 1 has on columns the kinds of management on each year and represents companies assess for each year. Companies of textile sector adopt D and C kinds of management mainly and their annual numbers have low variation. This alternative behavior of companies allows to do qualitative and quantitative analysis. The first one analyzes the adjustment of sector to changes of markets and second one analyzes what measures adopt companies to overcome those changes and how their alternative answers affect to financial structure of companies. To develop both analyses, the manuscript considers that companies adopt kinds of management as answer to change of market and to the environment where they are located, these answers generate tensions on management areas of kinds of management, which affect to financial and result structures of companies. So that, evaluation the activity of companies fallows the sequence of figure 2 . 


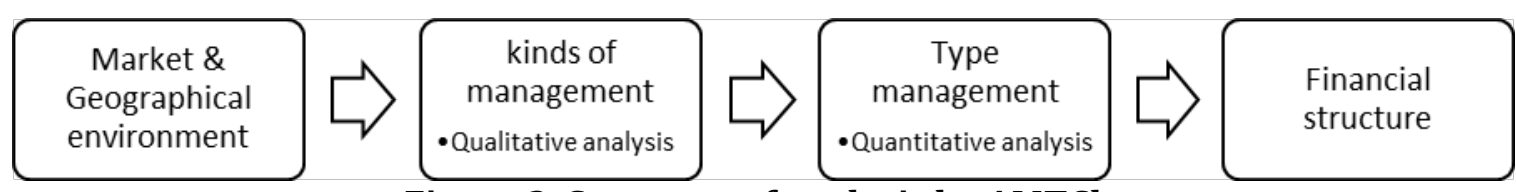

Figure 2. Sequence of analysis by AMTCh.

\section{Qualitative analysis.}

The qualitative analysis measure answers companies to change market in an environment where they are located. The table 2 are numbers of kinds of management in countries where there is textile industrial activity.

Table 2. Kinds of management by country

\begin{tabular}{|c|c|c|c|c|c|c|c|c|}
\hline \multirow[b]{2}{*}{ Country } & & & & & & & & \\
\hline & Domain & $\mathrm{A}$ & $\mathrm{B}$ & $\mathrm{C}$ & $\mathrm{D}$ & E & $\mathrm{F}$ & SUM \\
\hline $\begin{array}{l}\text { Great } \\
\text { Brittain }\end{array}$ & GB* $^{*}$ & 4 & 12 & 2 & 46 & 0 & 0 & 64 \\
\hline Turkey & TR* & 8 & 1 & 16 & 5 & 1 & 4 & 35 \\
\hline Pakistan & $\mathrm{PK}^{*}$ & 5 & 24 & 90 & 157 & 19 & 2 & 297 \\
\hline Egypt & $E^{*}$ & 0 & 0 & 0 & 7 & 3 & 0 & 10 \\
\hline Taiwan & TW* & 0 & 0 & 4 & 26 & 0 & 0 & 30 \\
\hline China & $\mathrm{CN}^{*}$ & 2 & 5 & 41 & 33 & 6 & 1 & 88 \\
\hline Thailand. & $\mathrm{TH}^{*}$ & 0 & 0 & 8 & 11 & 0 & 0 & 19 \\
\hline Japon & JP* & 0 & 0 & 1 & 5 & 2 & 2 & 10 \\
\hline Latvia & $\mathrm{LV}^{*}$ & 2 & 0 & 4 & 9 & 14 & 1 & 30 \\
\hline South Korea & $\mathrm{KR}^{*}$ & 8 & 2 & 15 & 101 & 43 & 25 & 194 \\
\hline Oman & $\mathrm{OM}^{*}$ & 0 & 0 & 0 & 7 & 3 & 0 & 10 \\
\hline Indonesia & ID* & 0 & 10 & 0 & 7 & 3 & 0 & 20 \\
\hline Italy & IT* & 62 & 33 & 95 & 36 & 17 & 12 & 255 \\
\hline Russia & $\mathrm{RU}^{*}$ & 0 & 0 & 15 & 13 & 10 & 2 & 40 \\
\hline France & FR* & 21 & 26 & 75 & 34 & 11 & 32 & 199 \\
\hline Estonia & EE* & 0 & 4 & 13 & 3 & 0 & 0 & 20 \\
\hline Austria & AT* $^{*}$ & 0 & 0 & 8 & 12 & 0 & 0 & 20 \\
\hline Finland & FI* & 0 & 3 & 8 & 9 & 0 & 0 & 20 \\
\hline Portugal & PT* & 0 & 0 & 7 & 3 & 0 & 0 & 10 \\
\hline Deutschland & DE* & 0 & 0 & 5 & 0 & 0 & 0 & 5 \\
\hline Belgium & BE* & 20 & 9 & 30 & 16 & 2 & 3 & 80 \\
\hline United States & US* & 0 & 0 & 4 & 26 & 0 & 0 & 30 \\
\hline Brazil & BR* $^{*}$ & 0 & 2 & 3 & 34 & 0 & 0 & 39 \\
\hline Sweden & SE* & 0 & 4 & 47 & 33 & 1 & 9 & 94 \\
\hline Bulgaria & BG* & 1 & 5 & 10 & 3 & 0 & 1 & 20 \\
\hline Slovakia & SK* & 8 & 11 & 8 & 20 & 2 & 1 & 50 \\
\hline Philipppines & $\mathrm{PH}^{*}$ & 5 & 5 & 0 & 0 & 0 & 0 & 10 \\
\hline & Sum KM & 146 & 156 & 509 & 656 & 137 & 95 & 1699 \\
\hline
\end{tabular}

The rows of table 2 are internet domain of countries $\left(^{*}\right)$ where activity of textile sector is located, and European countries adopt positive kinds of management, excluding United Kingdom (GB), Latvia (LT) and Austria (AT). This different behavior will be analyzed in a section to explain application of AMRCh on companies located in this country.

To measure making-decision processes table 3 present the parameters Chi $2 \mathrm{p}$-values for years and countries and according to level of the association of kMs respect to countries and years the statistic defines level of perturbation in textile sector. 
Table 3. Chi2 p-value of years and location

\begin{tabular}{|c|c|c|c|c|c|c|c|}
\hline Years & Chi2 p-value & Country & Chi2 p-value & Country & Chi2 p-value & Country & Chi2 p-value \\
\hline 2008 & 0,0137864 & $\mathrm{~GB}^{*}$ & 0,92773652 & $\mathrm{OM}^{*}$ & 0,350485212 & US* & 0,030181133 \\
\hline 2009 & $3,2148 \mathrm{E}-06$ & $\mathrm{TR}^{*}$ & 0,60909385 & ID* & 0,998803039 & $\mathrm{BR}^{*}$ & 0,528672479 \\
\hline 2010 & 0,00115157 & $\mathrm{PK}^{*}$ & 0,491015 & IT* & 0,963627279 & SE* & 0,935727701 \\
\hline 2011 & 0,00053584 & $\mathrm{EG}^{*}$ & 0,35048521 & $\mathrm{RU}^{*}$ & 0,999941682 & $\mathrm{BG}^{*}$ & 0,828671494 \\
\hline 2012 & $5,4339 \mathrm{E}-05$ & $\mathrm{TW}^{*}$ & 0,64512805 & $\mathrm{FR}^{*}$ & 0,696468737 & $\mathrm{SK}^{*}$ & 0,830082588 \\
\hline 2013 & 0,00115759 & $\mathrm{CN}^{*}$ & 0,31293257 & EE* & 0,688184685 & $\mathrm{PH}^{*}$ & 0,350485212 \\
\hline 2014 & 0,05079555 & $\mathrm{TH}^{*}$ & 0,97833782 & $\mathrm{AT}^{*}$ & 0,949601996 & & \\
\hline 2015 & 0,00532638 & $\mathrm{JP}^{*}$ & 0,31415383 & $\mathrm{FI}^{*}$ & 0,36494833 & & \\
\hline 2016 & 0,0001676 & $\mathrm{LV}^{*}$ & 0,99858853 & $\mathrm{PT}^{*}$ & 0,350485212 & & \\
\hline 2017 & 0,00725731 & $\mathrm{KR}^{*}$ & 0,91740036 & BE* & 0,723014177 & & \\
\hline
\end{tabular}

Results of table 3 show that this activity has ever difficult yearly because Chi2 p-value fulfills the null hypothesis, so there is not an associated behavior among years and countries, and this activity can to change of countries. Nevertheless, analysis by countries shows there is relation among years and kinds of management because Chi2 p-values is approaching to fulfill null hypothesis sometimes and others time does not fulfill it. When a country does not fulfill the null hypothesis there is not any perturbation to develop textile activity because there is a same answer continued each year, so there is a maintained kind of management in a country in period of analysis.

The adopting kinds of management is associated to level of tension of activity on management areas. Table 4 are sum of perimeter distances and have calculated Pearson's coefficient of variation (VP), their maximum and minimum for each year (MAXY, MIXY) and kind of management (MAXKM, MINKM).

Table 4. Sum of Perimeter Distances

\begin{tabular}{|c|c|c|c|c|c|c|c|c|c|}
\hline YEAR & SUM A & SUM B & SUM C & SUM D & SUM E & SUM F & V.P & MAXKM & MINKM \\
\hline 2008 & 21734 & 12741 & 15232 & 37514 & 2047 & 1673 & 0,88648 & D, A & F, E \\
\hline 2009 & 57117 & 31902 & 33502 & 45265 & 2258 & 2242 & 0,78098 & A, D & F, E \\
\hline 2010 & 60774 & 21687 & 27773 & 44826 & 2453 & 3530 & 0,85620 & A, D & E, F \\
\hline 2011 & 70474 & 19181 & 27746 & 45312 & 8619 & 1949 & 0,88024 & A, D & F, E \\
\hline 2012 & 90788 & 39789 & 27581 & 58866 & 7832 & 2601 & 0,87463 & A, D & F, E \\
\hline 2013 & 36960 & 42237 & 66385 & 47344 & 7612 & 3471 & 0,71216 & C, D & F, E \\
\hline 2014 & 29216 & 27020 & 36557 & 50787 & 5191 & 3422 & 0,72213 & D, C & F, E \\
\hline 2015 & 13838 & 25338 & 52761 & 52267 & 5763 & 3193 & 0,87295 & C, D & F, E \\
\hline 2016 & 20388 & 21396 & 51217 & 45602 & 13335 & 3626 & 0,71820 & C, D & F, E \\
\hline 2017 & 16544 & 20680 & 48495 & 50636 & 5444 & 10220 & 0,76930 & D, C & E, F \\
\hline V.P & 0,6322 & 0,3554 & 0,4003 & 0,1190 & 0,5769 & 0,6775 & & & \\
\hline MAXY & 2012 & 2013 & 2013 & 2012 & 2016 & 2017 & & & \\
\hline MINY & 2015 & 2008 & 2008 & 2008 & 2008 & 2008 & & & \\
\hline
\end{tabular}

The sum of perimeter distances (SUM) measure tensions of general activity of companies. Values of table 3 are sum perimeter distances on several areas of management and the analysis by year shows D kind of management has high level of annual sum on each year. So, there is low level of dynamic activity when companies adopt D kind of management. The Pearson's variation coefficients (V.P) are high on 2008, 2011, 2012,2013 and 2015, they are years with instability on activity. The stability of activity is on last years, when V.P adopt low level and companies adopt $\mathrm{C}$ and $\mathrm{D}$ kinds of management on column MAXKM. Companies avoid take $\mathrm{E}$ and $\mathrm{F}$ kind of management because tension on areas is higher than other Kinds of management. 
The transversal analysis measures stability of sum of PDk for each kind of management as well as the obtaining years with low level of tension on management areas. Transversal results show D kind of management with high level of stability according to value of Pearson's coefficient variation $(0,119)$ and years with high value of sum have been obtained for each kind of management on bottom of table 4. So, adopting D kind of management the 2012 year has low level of tension on management activity of company and 2008 year presents difficult on activity due to high level of tension on management areas.

The longitudinal as well as transversal analysis shows that companies do not take same kinds of management, and table 4 explains level of variation of tension among years and types of management. So, the adopting a kind of management to answer changes of market has different effects on financial statement, but these issues have also relation with location of companies. Section four analysis the effect of their location on a geographical area, working over hypothesis that economic culture of region has effect on the adopting a kind of management too.

\section{MAPS OF MANAGEMENT OF ENGLAND TEXTILE SECTOR Geographical location of textile sector.}

This section analyzes the relation among the adopting kinds of management and their geographical location in United Kingdom. British companies adopt B and D kinds of management and their location in United Kingdom are on figure 3 applying tools of Google Maps. Nevertheless, the adaptation kinds of management have relation with regional environment where companies are located.

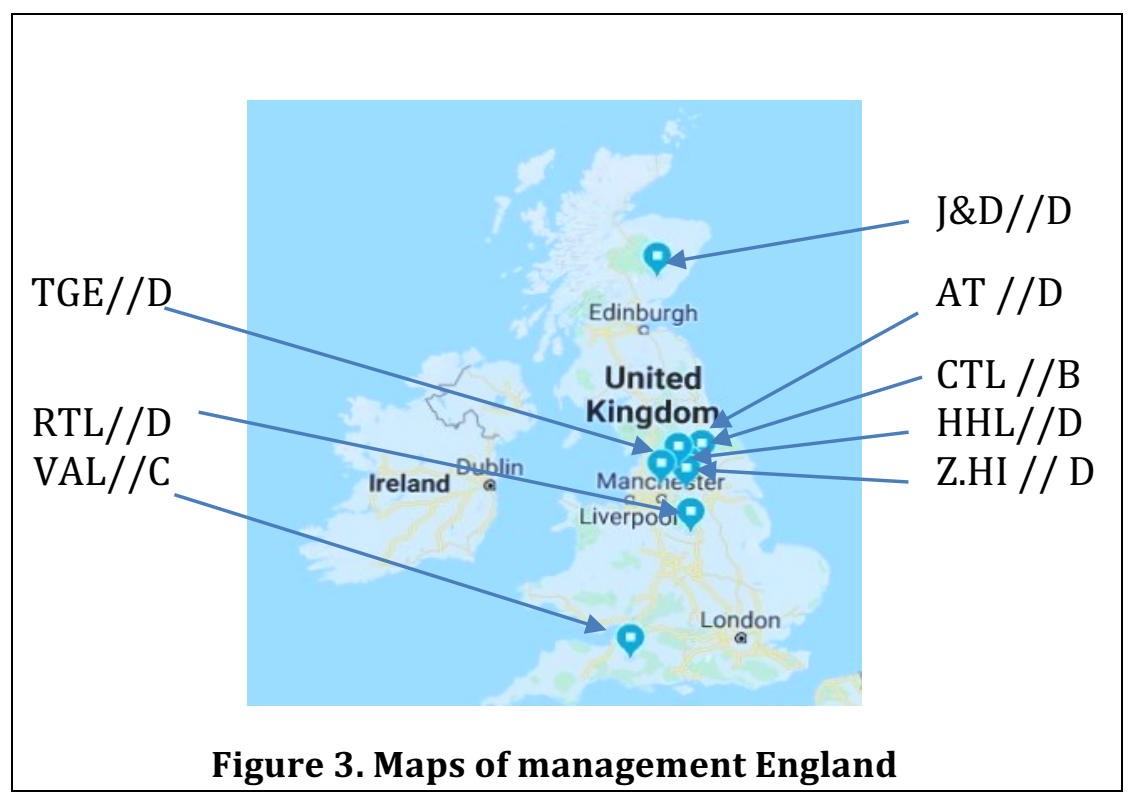

The result of research shows that companies located on geographical areas where there is high level of communication means adopt B (positives) kinds of management but companies located where level of communications means are lower than first one adopts $D$ (negative) kinds of management on figure 1 . The adopting a kind of management must be supported by different financial and economic structures and next figures justifies this hypothesis. 


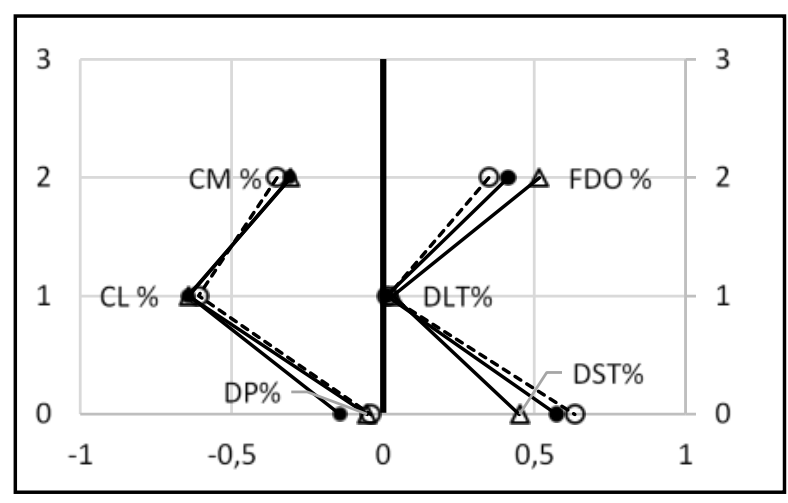

Figure 4. CTL //B ; 2011( $(\Delta) ; 2014(0) ; 2017(\bullet)$

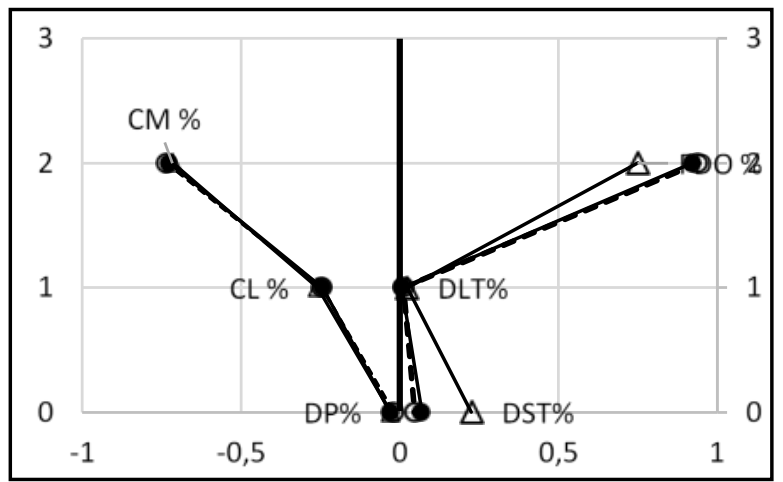

Figure 5. ZHI // D; 2011( $(\Delta) ; 2014(0) ; 2017(\bullet)$

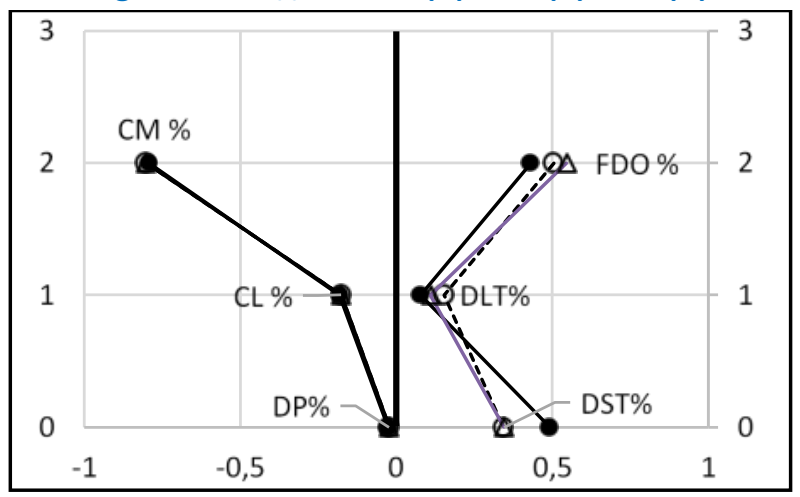

Figure 7. J\&D//D; 2011( $(\Delta) ; 2014(0) ; 2017(\bullet)$

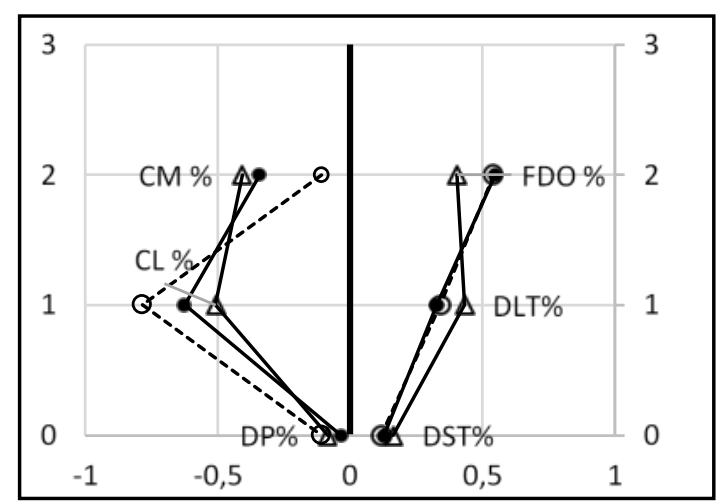

Figure 5. VAL//C; 2011( $(\Delta) ; 2014(0) ; 2017(\bullet)$

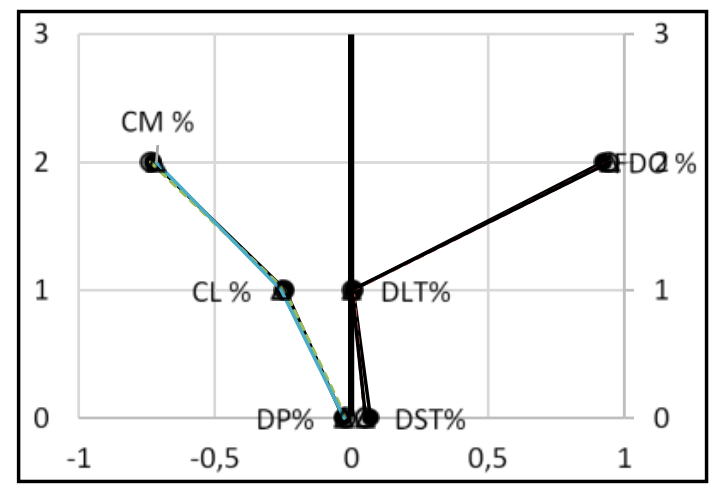

Figure 6. HHL//D; 2011( $(\Delta) ; 2014(0) ; 2017(\bullet)$

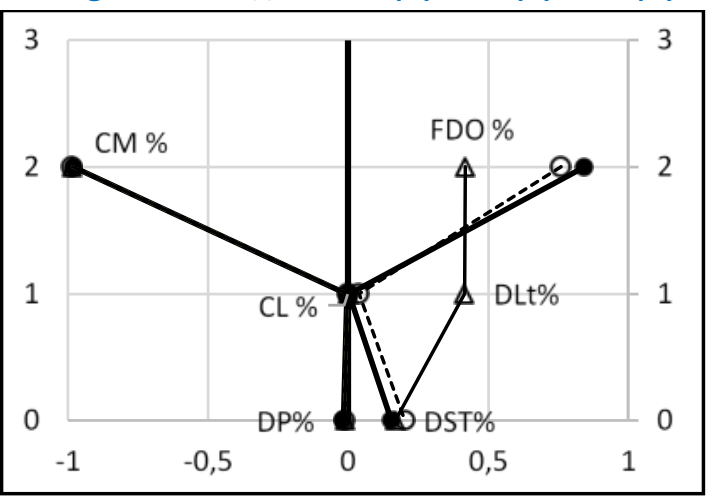

Figure 8. GEO//D; 2011( $(1) ; 2014(0) ; 2017(\bullet)$

The financial structure and cost of goods sold of companies located in United Kingdom are represented by criterium of Stiff's graphics on from figure 4 up to 8 . Their bottoms represent structure of costs of goods sold with negative percentages and financial structures have positive percentage. So, several level of y-axis represents percentages to both variables: Depreciation (DP\%) and Debts Sort Term (DST\%) are on level cero, Cost of Labor (CL\%) and Debts Long Term (DLT\%) are on level 2 and Cost of Material Row (CM\%) and Funds of Shareholders (FDO\%) are on level 3. According to results of research, companies with high level of percentages on CL\% and Debts adopt positives kind of management and, on the contrary, companies with high level on CM\% and FDO\% adopt negative kind of management.

Resume, levels of communication means have relation with Krugman's theory of location companies. They change levels of regional rents per capita, which have effect on conditions of transactions. So, the description of regional environment is a factor to consider on location of 
companies because it has effect on kind of management adopted by companies as well as on their financial and economic structures. The behavior of stakeholders is not indifferent to the regional environment where companies are located, and transactions of the decision-making process have that economic and financial cultures of environments. According to result of research, the economic and financial structures of companies are different in a same sector because it has relation with adopted kind of management, which is a consequence of economic cultures of regional environments where companies are located, and these factors do not entry on contradiction on theories of location companies as well as costs of transaction of Williamson.

\section{Quantitative analysis.}

Quantitative analysis considers the general effects of kinds of management on financial structure of companies. The Stiff's graphics have explained the individual financial and economic structures of companies and this section analyzes general financial structure of kinds of managements of companies. The Gibb's graphic or three-plot diagram is the tool applied to explain behavior of companies and variables of financial structure of England companies are in figure 9.

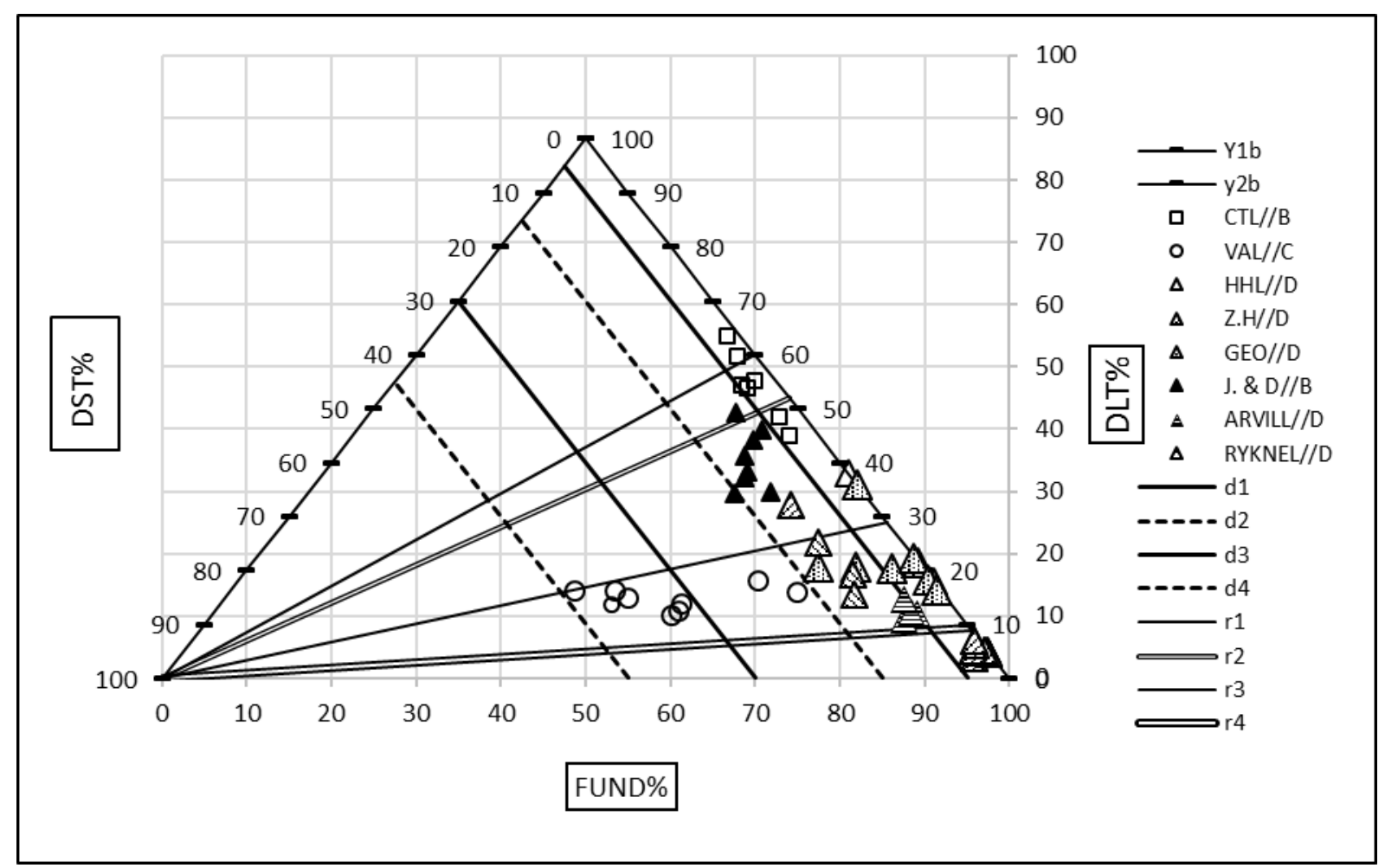

Figure 9. Three plot diagram of financial structures England companies.

The three-plot diagram allows analyzing variables of financial structure of companies represented on figure 9 and they are too in Stiff's graphics of above section. Triangles of figure 9 represent negative and positives kinds of management and they have associated circles and squares respectively. Each observation of three-plot sum percentages of three variables and sum 100\%. To understand company behaviors are represented diagonals (di) and ratio lines (rj) between variables. Diagonal represents limits of behavior of tow variables which sum is $100 \%$, excluding the third variable, and ratio lines are relation of two variables where this line cross on a triangle side. The table 5 are value of different lines represented in figure 9. 
Table 5. Diagonal and ratios figure 9

\begin{tabular}{|c|c|c|c|}
\hline Diagonal lines & FUN\% \& DST\% & Ratio lines & DLT\%/FUN\% \\
\hline D1 & $95 \%$ \& 5\% & R1 & $52 / 69,977786=0,743092958$ \\
\hline D2 & $85 \% \& 15 \%$ & R2 & $45 / 74,0192379=0,607950058$ \\
\hline D3 & $70 \% \& 30 \%$ & R3 & $25 / 85,5662=0,292171294$ \\
\hline D4 & $55 \% \& 45 \%$ & R4 & $8 / 95,38119785=0,083873973$ \\
\hline
\end{tabular}

According result of table 5, there are several sides to explain sources to financial companies.

$\circ$ Area 1. The area limited by D1 and R4 defines companies with negative kinds of management (triangles). Their sources of financial are 5\% on total liability is Debt on short term and Debt on long term represent 8,38\% of Funds of Shareholders.

- Area 2. The area limited by D2, R4 and R3 defines negative kinds of management of companies (triangles). The sources of finance are 15\% on total liability is Debt on short term and Debt on long term represents $29,217 \%$ of Funds of Shareholders.

- Area 3. The area limited by D1, D2, R3 and R2 defines negative kinds of management of companies (triangles). The level of Debt on short term is between $5 \%$ and $15 \%$ on total liability and Debts on long term are between $29,217 \%$ and $60,79 \%$ of Funds of Shareholder funds.

- Area 4. The area limited by D1, R2 and R1 defines positive kinds of management (square). The financial sources are $5 \%$ on total liability is Debt on short term and Debt on long term represents $60,79 \%$ and $74,31 \%$ on Funds of Shareholders.

- Area 5. The area limited by D3, D4, R3 and R4 defines positive kinds of management (circles). The financial structure is Debt on lo long term which represents $29,21 \%$ and $3,38 \%$ on Funds of Shareholders and level of financing by Debt on sort term is between $30 \%$ and $45 \%$ on total liabilities.

The three-plot diagram represents positions of financing that companies obtain to maintain their activity according to kinds of management adopted as answer to changes of markets and environments where companies are located. The Funds of Shareholders take relevance when kinds of management are negative and Debts on sort and long term take relevance when those are positive. The finance structure of companies was contrasted with structure of cost of goods sold by Stiff's graphics but considering singular decisions of companies. According to results on both graphics, there are relations among kinds of management and economic and financial structures of companies and it has relation with location of companies.

\section{Kind of management and financial structure.}

The multidirectional effects of making-decision process on financial and economic structures of companies was analyzed on above sections. This section explains relations among angular indicators of sufficiency and liquidity transactions conditions of AMRCh and changes on financial structure of companies. The evolution of tow type of variables is on figure 10 and 11 respect to companies which radar charts are on figure 1 . Series of both figures with dashed lines are financial structures variables and series represented by continued lines are angular relations of sufficiency and liquidity transactions of AMRCh. Moreover, according to radar charts of figure 1, company CTL adopts positive Kind of management B and company HHL adopts negative Kind of management $\mathrm{D}$, and their perimeter distances are different. The CTL company has less tension on purchases area than HHL company and it justifies the obtaining more financing from markets than HHL, which has less tension on sales area than other areas of management as well as it has more dilated time on liquidity transaction on sales area than CTL company. 


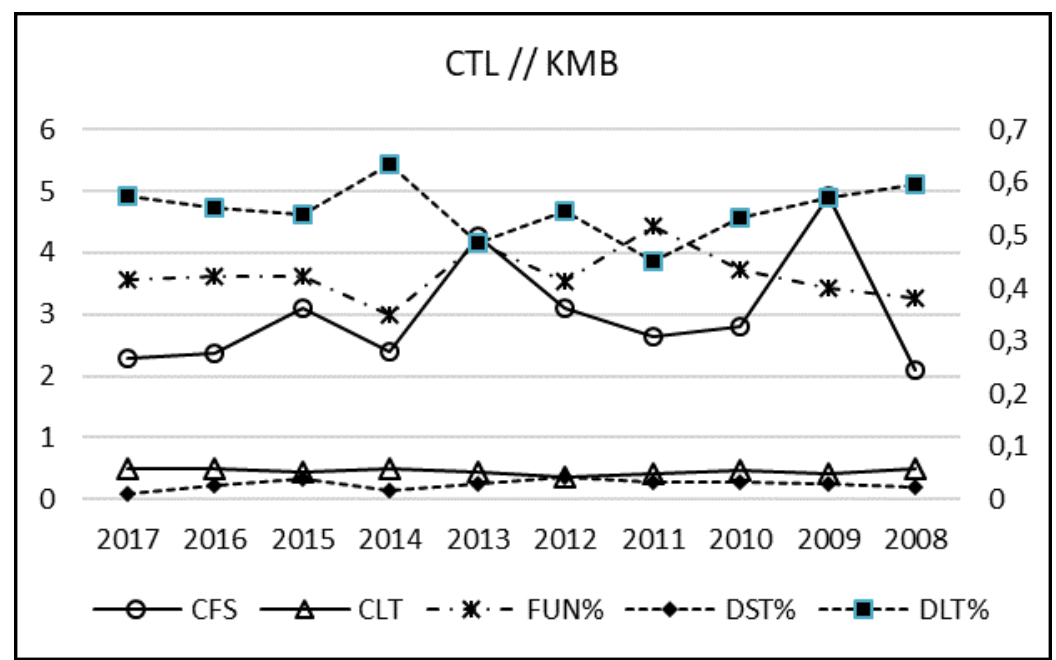

Figure 10. Relations among financial and angular ratios of CTL company.

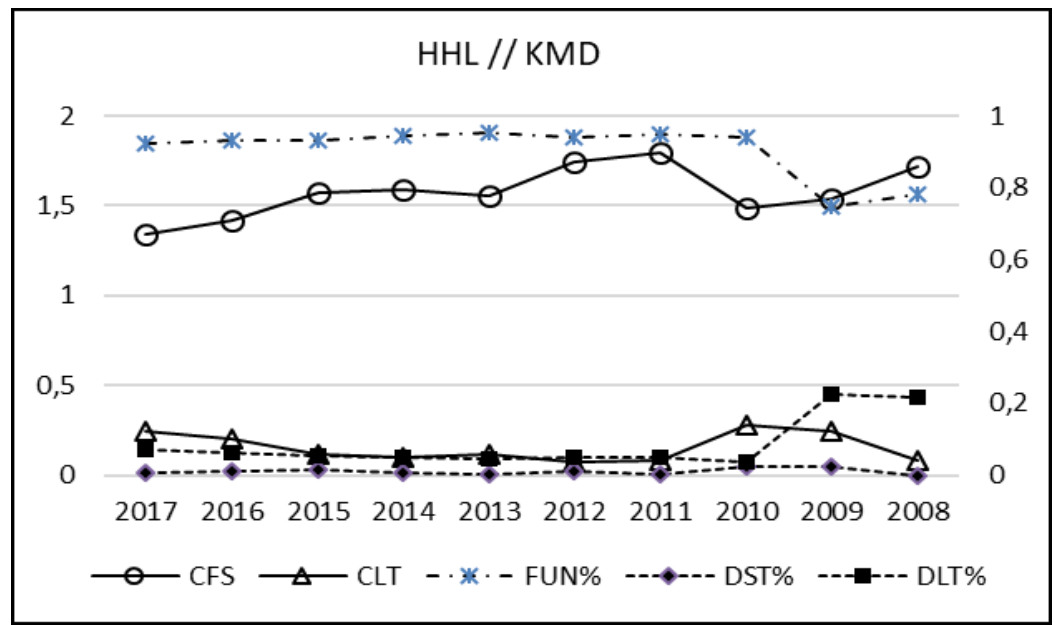

Figure 11. Relations among financial and angular ratios of HHL company.

The change of financial structures has its cause about approaching the angular ratios of financial and liquidity transactions conditions. The evolution of series in figure 10 represents evolutions of angular ratios of treasure area and variables of financial structure of CTL company. These last variables are represented on dashed line, taking reference the secondary $\mathrm{y}$-axis, and variables of financial structure take reference on primary $\mathrm{y}$-axis, been represented by continued lines. The company CTL increases its Debt on sort term (EST\%) when ratio of series $1(\beta 1 / \alpha 3>1)$ is next to ratio of series $2(\alpha 1 / \beta 3>\mathrm{PC} / \mathrm{PP})$. The evolution of series in figure 11 have a different criterium because financial sources of Fund of Shareholders (FUN\%). So, when difference between angles ratio of financial sufficiency $(\beta 1 / \alpha 3>1)$ and liquidity of transaction $((\alpha 1 / \beta 3>\mathrm{PC} / \mathrm{PP})$ decreases the financial source that supports the lack of liquidity of financial sufficiency is the Fund of Shareholders (FUN\%).

The different ways to finance the lack of liquidity is associated to kind of management adopted by companies as answers to perturbations of market and environment where they are located. CTL company adopts positive Kind of management (B) and HHL adopts negative kind of management $\mathrm{D}$, they are two ways for answering the perturbation of economies. So, the adopting positive kind of management supposes that financial sources will be the Debt on short and long term and companies obtain credit from markets. Nevertheless, when companies adopt negative kinds of management, they are financing markets increasing their Funds of Shareholders. This effect has been analyzed on previous section and can be consider as a general effect when companies adopt a kind of management. 


\section{CONCLUSION}

The making-decision process of a company can be assessed by several ways. Nevertheless, the rational criterion of managers and the asymmetry of accounting information are factors included in performance of companies. This manuscript considers that both factors are present on answers of companies to changes of markets as well as to changes on geographical environment where they are located. The accounting methodology of radar chart measures the multidirectional effect of making-decisions process on management areas represented on a radar chart generating kinds of management, which are classified according to level of tension on them. The relation among kinds of management of companies and their structures of financing and cost of goods sold are visualized by graphics of Gibbs and Stiff. The visualization of accounting variables aims to explain the casuistry obtained in the manuscript without using heuristic methods to emphasize on the validity of hypotheses suggested in it. Resume, simply the companies are economic agents, which adopt the cultures of societies in which they live, among them the economic and financial ones.

\section{References}

Peprah, W. K., \& Ganu, J. (2018). The Convergence of Organizational Culture, Structure and Human Capital Performance: A. Conceptual Analysis. Archives of Business Research, 6(5), 212-221.

Iammarino,S., Rodriguez-Pose, A and Storper, M. Regional inequality in Europe: evidence, theory and policy implications. Journal of Economic Geography (2018) pp. 1-26.

Capello, R., Caragliu, A. \& Fratesi, U. Measuring border effects in European cross-border regions, Regional Studies. 2018. 52:7, 986-996.

Committee of Sponsoring Organizations of the Treadway Commission. (COCO). Enterprise Risk Management — Integrated Framework. https://www.coso.org

Regulation (EU) No 575/2013 as regards transitional arrangements for mitigating the impact of the introduction of IFRS 9 on own funds and the large exposures treatment of certain public sector exposures denominated in nondomestic currencies of Member States. https://www.consilium.europa.eu /media/31550/st_13725_2017_init_en.pdf

GRI 102: GENERAL DISCLOSURES. https://www.globalreporting.org/standards/media/1036/gri-101foundation-2016.pdf

Code Federal Regulation. U.S.. 17 CFR 229.303 (Item 303) Management's discussion and analysis of financial condition and results of operations. https://www.gpo.gov/fdsys/

Comisión Nacional del Mercado de Valores. Guide for the preparation of management reports of listed companies. https://www.cnmv.es/portal/home.aspx.

Perez-Benedito, M. A. (2015). The Application of Accounting Mehodology of Radar Charts to Analyze the Sector of Swmilling and Planning of Wood of Austria. Archives of Business Research, 3(4), 1-14.

Perez-Beneditio, M.A., Porcuna-Eguix, Luis and Porcuan-Enguix, Ruben. Main drivers of management behaviour through accounting methodology of radar charts: evidence from italy. Conference: European Accounting Association (EAA) 41st Annual Congress. At: Milan, Italy. May 30 - June 1, 2018. https://www.researchgate.net/publication/324648249_MAIN_DRIVERS_OF_MANAGEMENT_BEHAVIOUR_THRO UGH_ACCOUNTING_METHODOLOGY_OF_RADAR_CHARTS_EVIDENCE_FROM_ITALY

Per-Benendito, M.A. The analysis of behavior of switzerland company by methodology of radar chart- European Journal of Business and Social Sciences, Vol.3, No. 6 , pp 136-155, September 2014. pp 136-155 136-155URL: http://www.ejbss.com/recent.aspxISSN: 2235-767X 